\title{
Evaluation of dietary protein intake by growing ostriches.
}

\begin{abstract}
The protein requirements of growing ostriches have not been established. In an effort towards more understanding of the animal's needs for this nutrient two trials were carried out to evaluate the intake of protein (GP) from complete feeds by growing ostriches. In trial I, the comparative response of ostriches to diets containing Pligh Protein (HP, 22.5\% GP), Medium Protein (MP, 17.5\% CP) or Low Protein (LP, $12.5 \%$ CP) protein content was determined, while the preference of these birds to the same three diets offered simultaneously in a freechoice feeding situation was investigated in trial II. Ostriches in trial I fed on HP or MP consumed more feed, gained more weight and were more efficient in converting feed to body weight than birds fed on LP. Differences in growth performance between the HP and MP groups were not significant. Birds on HP consumed more protein than those offered MP but this was not translated into superiority in growth. In trial II, where ostriches were offered either a sole MP feed or a free-choice of HP, MP and LP given simultaneously, birds on the single complete feed were more efficient in converting feed and protein into body weight than choice-fed animals. In choice feeding, MP was consumed at a significantly higher amount and proportion than that of either HP or LP which, between themselves was consumed in similar amounts. It was concluded that among the three diets studied, a medium protein feed with a GP content of $17.5 \%$ was most economical and optimum for growing ostriches. When presented with a choice of feeds with varying protein contents these birds were not able to select well for optimum growth performance.
\end{abstract}

Keyword: Growing ostriches; Protein level; Choice feeding; Growth. 